\title{
Family Caregivers as Partners in Care Transitions: The Caregiver Advise Record and Enable Act
}

\author{
Eric A. Coleman, MD, MPH*
}

Division of Health Care Policy and Research, University of Colorado Denver Anschutz Medical Campus, Aurora, Colorado.

The objective of this Perspective was to provide guidance to hospitalists and hospital clinical leadership on how to implement the Caregiver Advise Record and Enable (CARE) Act, which has been passed into law in 30 US states and territories. Specifically, the objective is 3-fold: (1) increase awareness among hospitalists and encourage them to begin to prepare for implementation, (2) explore the impetus for this legislation, and (3) provide a list of suggested resources geared to both family caregivers and healthcare professionals that may be helpful in preparation for implementing the CARE Act. Journal of Hospital Medicine 2016;11:883885. (C) 2016 Society of Hospital Medicine.
Under the national leadership of AARP, 42 states and territories have introduced the Caregiver Advise Record and Enable (CARE) Act, 32 have passed it, and the following 30 have enacted it into law: Arkansas, California, Colorado, Connecticut, District of Columbia, Illinois, Indiana, Louisiana, Maine, Maryland, Michigan, Minnesota, Mississippi, Nebraska, Nevada, New Hampshire, New Jersey, New Mexico, New York, Oklahoma, Oregon, Pennsylvania, Puerto Rico, Rhode Island, Utah, Virginia, Virgin Islands, West Virginia, Washington and Wyoming (as of June 6, 2016). The CARE Act requires hospitals to: (1) record the name of the family caregiver in the medical record, (2) inform the family caregiver when the patient is to be discharged, and (3) provide the family caregiver with education and instruction on the medical tasks that he or she will need to perform for the patient upon return home. ${ }^{1,2}$

The family caregiver is to be identified by the patient. Because the patient is the source of the information, Health Insurance Portability and Accountability Act concerns are minimal. A family caregiver need not be related to the patient by blood or marriage; a friend, neighbor, partner, or paid caregiver could be identified by the patient as serving in this role. If the patient does not identify a family caregiver (due to the absence of such an individual, concern for potential burden on a loved one, desire for confidentiality, transient or progressive cognitive impairment, or other reasons), this also needs to be documented, though the additional provisions of the CARE Act would not

*Address for correspondence and reprint requests: Eric A. Coleman, MD, University of Colorado Denver Anschutz Medical Campus, 13199 East Montview Blvd., Suite 400, Aurora, CO 80045-7201; E-mail: eric. coleman@ucdenver.edu

Additional Supporting Information may be found in the online version of this article.

Received: March 29, 2016; Revised: June 7, 2016;

Accepted: June 13, 2016

2016 Society of Hospital Medicine DOI 10.1002/jhm.2637

Published online in Wiley Online Library (Wileyonlinelibrary.com). be applicable. As some states have made additions or individual modifications to the CARE Act, the reader is encouraged to learn more about state-specific differences that might impact implementation., ${ }^{2,3}$

The impetus for the CARE Act emerges from challenges faced by both family caregivers and healthcare professionals. The 3 care elements included in the Act appear to have considerable face validity for what would constitute good transitional care. To further explore why this is necessary, we need to begin by asking why are these 3 care elements not routine, and why did an advocacy organization resort to a legislative solution to formally recognize and include family caregivers in discharge preparation?

Family caregivers, when able and willing, often play an instrumental role in the care of their loved ones, particularly during the vulnerable time of transitions out of the hospital. ${ }^{4,5}$ They are often the first line of defense for detecting lapses in quality or safety as care is transitioned from the hospital. Family caregivers frequently take on a primary or secondary role in operationalizing and executing the discharge plan. Nearly half of family caregivers perform skilled medical or nursing tasks for their loved ones (eg, wound care, injections, complex medication management, operating specialized medical equipment) often with insufficient assistance or training from healthcare professionals. $^{6}$

Lack of sufficient time might be a major reason why the 3 care elements identified in the CARE Act are not routinely addressed by the discharging team, which may include hospitalists, nurses, pharmacists, social workers, and other clinicians. However, there may be other reasons as well, including a lack of knowledge, confidence, or tools for how to best prepare the patient and family caregiver. This is compounded by the absence of routine feedback loops for gauging the effectiveness of discharge preparation beyond a patient's readmission to the same facility. If hospital-based clinicians were asked to rank order their daily tasks from greatest sense of professional 
TABLE 1. Selected Websites That Promote the Role of Family Caregivers in Discharge Preparation.

\begin{tabular}{|c|c|}
\hline Organization (URL) & Relevant Resources for Implementing the CARE Act \\
\hline AARP (www.aarp.org/nolongeralone) & Family caregiver video guides to managing medications \\
\hline \multirow{5}{*}{$\begin{array}{l}\text { Alzheimer's Association } \\
\text { (http://www.alz.org/documents/ } \\
\text { national/topicsheet_hospitaldischarge.pdt) }\end{array}$} & Addresses the unique needs of persons with dementia: \\
\hline & Ensuring that all treating physicians and medical professions are aware of the diagnosis of Alzheimer's or other dementia \\
\hline & $\begin{array}{l}\text { If the person with dementia has difficulty communicating, the family caregiver may help medical staff by offering suggestions about what the person may } \\
\text { want or need }\end{array}$ \\
\hline & The family caregiver may alert medical staff of triggers that may cause unpredictable behavior \\
\hline & Considerations for discharge to a residential facility or assisted living \\
\hline \multirow{6}{*}{$\begin{array}{l}\text { Care Transitions Program } \\
\text { (http://caretransitions.org) }\end{array}$} & Provides a wide range of resources for professionals, patients, and family caregivers: \\
\hline & The FCAT tool \\
\hline & Hospital discharge checklist \\
\hline & Tips for managing care at home \\
\hline & Tips for recognizing and responding to red flags \\
\hline & Tips for effective medication management \\
\hline \multirow{5}{*}{$\begin{array}{l}\text { Insititute for Patient- and Family-Centered Care } \\
\text { (http://www.ipfcc.org/advance/Advisory_ } \\
\text { Councils.pdf) }\end{array}$} & Offers practical advice for establishing patient and family advisory councils: \\
\hline & Qualities and skills of patientffamily advisors \\
\hline & Recruitment \\
\hline & Development of bylaws \\
\hline & Meeting schedule \\
\hline \multirow{4}{*}{$\begin{array}{l}\text { National Transitions of Care Coalition } \\
\text { (http://www.ntocc.org) }\end{array}$} & Provides a wide variety of tools and resources: \\
\hline & Taking Care of MY Health Care developed as a guide to help patients and family caregivers feel better prepared \\
\hline & My Medicine List helps patients and family caregivers gather important information about medications \\
\hline & $\begin{array}{l}\text { Cultural competence tool provides strategies and resources to enhance professionals' capacity to deliver culturally competent services to patients and family } \\
\text { caregivers during transitions of care }\end{array}$ \\
\hline \multirow[t]{6}{*}{ Next Step in Care (http://www.nextstepincare.org) } & The most comprehensive site supporting both family caregivers and health professionals; includes: \\
\hline & A toolkit for working with family caregivers \\
\hline & HIPAA considerations for family caregivers \\
\hline & Tips on identifying the family caregiver \\
\hline & Assessment tool for family caregivers' needs \\
\hline & Tips for referring patients and family caregivers to community-based services \\
\hline Project BOOST & Extensive toolkit includes: \\
\hline (http://www.hospitalmedicine.org/about_shm/web- & Self-assessment questions to promote planning for how to include family \\
\hline formz/form_wfz_imptk_boost.aspx??FormSubmission- & Return on investment calculator that includes patient as well as family satisfaction \\
\hline \multirow{2}{*}{ Key=21301dd3-5c5f-4a68-25e7-15fa1d0c01eb) } & Teach back approach applicable to patient and family caregivers \\
\hline & Patient and family caregiver preparedness tool \\
\hline Project RED & Extensive toolkit includes: \\
\hline (https://www.bu.edu/fammed/ & Five steps to integrating family caregivers into the discharge plan \\
\hline projectred/) & Understanding and enhancing the role of family caregivers in RED \\
\hline
\end{tabular}

NOTE: Abbreviations: BOOST, Better Outcomes by Optimizing Safe Transitions; CARE, Caregiver Advise Record and Enable; FCAT, Family Caregiver Activation in Transitions; RED, Re-Engineered Discharge.

gratification to lowest, discharge preparation would likely appear toward the bottom of the list. ${ }^{7,8}$

Meanwhile, hospitalists and hospital clinical leaders are struggling to keep pace with a confluence of new demands that include value-based purchasing initiatives and population health efforts, to name but a few. Although current Centers for Medicare and Medicaid Services' (CMS) Hospital Conditions of Participation for Discharge Planning do not require recognition or preparation of family caregivers, CMS' newly proposed revisions emphasize better preparation of family caregivers to be active partners upon hospital discharge. ${ }^{9}$ Thus, although it might be reflexive to view the CARE Act in isolation as yet 1 more initiative requiring new effort and resources to address, widening the lens may confirm that the contributions of family caregivers are integral and aligned across nearly all efforts aimed at promoting greater value, and in this light could be viewed as complementary rather than competitive.
Innovation or new resources may be needed to implement the CARE Act. In the absence of a step-bystep user's guide, hospitals may wish to take advantage of valuable publicly available resources that encourage more effective collaboration between family caregivers and healthcare professionals (Table 1).

Operationalizing the CARE Act may initially appear simple but in practice will not be easy. The first care element focuses on identifying the family caregiver. Next, Step in Care offers a practical guide for how to identify the family caregiver in a busy hospital environment (Table 1). The guide advises health professionals on how to identify the person most likely to assume responsibility for care after discharge by asking a series of questions: Who assists you at home? Who do you call in case of emergency? Who helps with medications or doctor appointments? The guide cautions health professionals not to assume that individuals encountered at the patient's bedside are necessarily the family caregivers. They may be covering for 
the family caregiver, who has other duties (eg, job, child care).

The second CARE Act element entails informing the family caregiver when the patient will be discharged. At present there is no standardization of this practice. Many hospitals conduct interdisciplinary rounds, during which a discharge date is frequently estimated. A designated member of the inpatient team (eg, primary nurse, social worker, care manager) might be tasked with notifying the family caregiver of this estimated date (either in person, by telephone, or using other approved mode[s] of communication). Ideally, this notification should be conveyed as soon as the inpatient care team can foresee a discharge date, as it would be preferable to give the family caregiver an estimate that turns out to be a day or 2 off and needs to be revised than to inform the family caregiver at the last minute. The white board in the patient's room may serve as a reminder to both the patient and family caregiver as well as to other members of the inpatient care team.

The third CARE Act element could be facilitated with the Family Caregiver Activation in Transitions (FCAT) tool, a self-efficacy measure of transition specific tasks. The FCAT tool is designed to facilitate more productive interactions and guide the care team in understanding what common transition-related areas family caregivers would like to feel more prepared for or confident with. The FCAT tool can be administered by a health professional or selfadministered by a family caregiver and takes approximately 2 minutes to complete ${ }^{10}$ (Table 1 ).

Hospital leaders might consider creating an interdisciplinary team charged with facilitating the implementation of the CARE Act. Specifically, this team might develop guidelines and serve as a forum whereby clinicians might share particularly challenging cases. Similarly, for ongoing input and suggestions for how to further improve all aspects of hospital care, including the discharge experience, hospitals are encouraged to form and foster patient and family advisory councils (Table 1).

Finally, when it comes to improving the hospital discharge experience for family caregivers, there is no "us and them." Despite our professional advantages, each of has had or will likely have an opportunity to overcome the many gaps in hospital discharge planning, not just as healthcare professionals but also in our roles as adult children, spouses, and parents. In this regard, we are all invested in improving the discharge experience.

\section{Disclosures}

Support for this work was provided by the Gordon and Betty Moore Foundation. The sponsor had no role in the preparation, review, or approval of this article. The author reports no conflicts of interest.

\section{References}

1. Ryan E. One caregiver's regret: how the CARE Act could have helped. Available at: http://blog.aarp.org/2016/04/18/one-caregivers-regrethow-the-care-act-could-have-helped. Published April 18, 2016. Accessed June 7, 2016.

2. Reinhard S, Ryan E. Stepping up to support family caregivers. Available at: http://blog.aarp.org/2016/06/07/stepping-up-to-support-family-caregivers. Published June 7, 2016. Accessed June 7, 2016.

3. Martinez JC. New state laws support millions of Americans who minister to aging relatives and form the backbone of the nation's longterm care system. Available at: http://www.ncsl.org/research/humanservices/helping-the-helpers.aspx. Published February 1, 2015. Accessed June 7, 2016.

4. Coleman EA, Roman SP. Family caregivers' experiences during transitions out of the hospital. J Healthc Qual. 2015;37:12-21.

5. Gillick MR. The critical role of caregivers in achieving patientcentered care. JAMA. 2013;310:575-576.

6. Reinhard SC, Levine C, Samis S. Home alone: family caregivers providing complex chronic care, 2012. Available at: http://www.aarp.org/ home-family/caregiving/info-10-2012/home-alone-family-caregiversproviding-complex-chronic-care.html. Accessed June 7, 2016.

7. Halasyamani L, Kripalani S, Coleman EA, et al. Transition of care for hospitalized elderly patients-development of a discharge checklist for hospitalists. J Hosp Med. 2006;1:354-360.

8. Greysen SR, Schiliro D, Horwitz LI, Curry L, Bradley EH. Out of sight, out of mind: housestaff perceptions of quality-limiting factors in discharge care at teaching hospitals. J Hosp Med. 2012:7:376-381.

9. Centers for Medicare and Medicaid Services. Proposed revisions to requirements for discharge planning for hospitals, critical access hospitals, and home health agencies. Fed Regist. 2015;80:6812568155.

10. Coleman EA, Ground KL, Maul A. The Family Caregiver Activation in Transitions tool (FCAT): a new measure of family caregiver selfefficacy. Jt Comm J Qual Patient Saf. 2015;41:502-507. 